more effectively coexist. To protect vulnerable individuals who may be treated with psychotherapy outwith the NHS appropriate standards of ethics, practice and training are essential for nonNHS psychotherapists. These psychotherapists should be able to recognise severe mental illness and have a basic understanding of psychotropic medication and psychiatric services.

\section{Acknowledgements}

We thank the service users and staff of the Number 21 Counselling Centre, Edinburgh as well as the patients of the Royal Edinburgh Hospital who agreed to be involved.

\section{References}

Amies, P. (1996) Psychotherapy patients: are they the worried well'? Psychiatric Bulletin. 20. 153-156.

ANDREWS, G. (1993) The essential psychotherapies. British Journal Psychiatry. 162, 447-451.

DEROGATIS, L. R. (1983) SCL-90-R: Administration, Scoring and Procedures. Towson. MD: Clinical Psychometric Research. Inc.

Doidge, N., Simon, B., Gilues, L. A., et al (1994) Characteristics of psychoanalytic patients under a nationalised health plan: DSM-III-R diagnosis, previous treatment, and childhood trauma. American Joumal of Psychiatry. 161, 586-590.

EVANS, J., HARTMAN, J. \& GladWELL, S. (1995) Diagnostic survey in a regional psychotherapy unit. Psychiatric Bulletin. 19, 673-675.
FurnhaM, A. \& WARDLEY, Z. (1990) Lay theories of psychotherapy 1: Attitudes towards, and beliefs about. psychotherapy and therapists. Joumal of Clinical Psychology, 46. 878-890.

HINSHELWOOD, R. D. (1994) The relevance of psychotherapy. Psychoanalytic Psychotherapy. 8. 283-294.

Holmes, J. \& MARKS, l. (1994) Psychotherapy - a luxury the NHS cannot afford? British Medical Journal. 809. 1070-1072.

MALONEY. C. (1993) Who should refer to psychotherapy? Referrals to a regional service. Psychiatric Bulletin. 17. 352-354.

MARGISON, F. \& STEWART, A. (1996) General practitioner and psychotherapist referrals to a specialist psychotherapy centre. Psychiatric Bulletin, 20, 418-421.

MoRTON, M. J. \& STAINES. J. (1993) GP use of psychotherapy services. Psychiatric Bulletin. 17. 526-527.

Royal COLLEge OF PSYChIATRISTS (1993) Psychological therapies for adults in the NHS: A joint statement by the British Psychological Society and the Royal College of Psychiatrists.

TASCA, G. A., RusseIL. V. \& BusBy, K. (1994) Characteristics of patients who choose between two types of group psychotherapy. International Joumal of Group Psychotherapy. 44, 499-508.

WoNG, J. L. (1994) Lay theories of psychotherapy and perceptions of therapists: a replication and extension of Furnham and Wardley. Journal of Clinical Psychology. 50. 624-632.

*John R. Mitchell, Senior Registrar, and Chris P. Freeman, Senior Lecturer in Psychiatry. Royal Edinburgh Hospital, Morningside, Edinburgh EH10 5HF

*Correspondence

\title{
Psychotherapy and old age psychiatry
}

\author{
Jane Garner
}

Alms and Methods This report was prepared as the basis for wider consultation within the Old Age Faculty and the College. Some literature and practice is reviewed and practical suggestions made for the future in this area.

Reaults Although older patients are less likely to be refused for psychological intervention attitudes are slowly changing.

Clinical implications The clinical implications of this development include a greater consideration of the unique emotional life of each of our patients and an improved understanding of our reluctance to engage in psychotherapeutic work with older people.

". . near or above the age of fifty the elasticity of the mental processes on which treatment depends is as a rule lacking - old people are no longer educable . . . (Freud, 1905).

Hildebrand (1982) points to a certain irony in these comments as Freud, at the age of 49 , was 
about to produce for the world a creative and revolutionary metapsychology. Nevertheless this negative view of age continues to permeate our youth-centred culture. Meerloo (1955) writes of treatment of life in decline as a wound to our medical narcissism. Zivian et al (1992) have shown that therapists prefer to work with younger patients. This negative view of ageing is carried by us all in our conscious and unconscious minds and is perhaps 'mirrored' in older people's view of themselves (Evans, 1988; Garner \& Ardern, 1998), particularly when depressed. The ruling market hegemony where human need is seen as despicable dependence and where "competition and survival ennoble the soul" (Bell, 1996) only serves to increase the vulnerability of patients who are doubly stigmatised as a consequence of being mentally ill and old (Ardern et al, 1998).

The reluctance to engage in psychotherapeutic work with this age group may have many roots: staff fears of their own ageing; unresolved conflicts about relationships with parents and grandparents; shifting and confusing multi-generational transferences: feelings of sadism or pity, of idealisation and reverence or of denigration and fear.

Old age psychiatrists who have in so many ways championed the cause of this patient group may nevertheless themselves unwittingly fall prey to some of the subtler prejudicial ideas and pay much more attention to biological and social assessment and management than to the psychological life of the older patient. When planning a new unit, project groups spend hours on the architecture, physical environment and space, with far less attention being spent on the psychological milieu of the unit; the emotional environment including space for staff to reflect on their work. Rightly, we protest that few purchasers have allowed the prescription of donepezil, but not many services incorporate all the psychological interventions which have been identified as successful. Speaking in 1995 , Bergmann (cited in Garner \& Evans, 1996) suggested that role expectation for elderly people is limited so that they are less likely to be recognised as being pathologically depressed. more likely to get tranquillisers and less likely to be referred for psychotherapy.

The National Health Service (NHS) Executive has reviewed strategic policy for NHS psychotherapy services in England (Department of Health. 1996). Three frameworks of delivery are suggested by the review; type A, psychological treatment as an integral component of mental health care (e.g. social skills training, anxiety management, family therapy, family meetings or counselling as part of a programme of care); type $B$, eclectic psychological therapy and counselling (this is informed from more than one theoretical base and constitutes a large proportion of psychological work undertaken by the NHS): type C, formal psychotherapy practised within particular theoretical models (e.g. cognitivebehavioural, psychodynamic, undertaken by or under the supervision of a trained specialist).

Work is already undertaken in old age services within these frameworks, particularly type $A$ and $B$, but staff need (and welcome) supervision which is not always readily available. It is helpful to read the review of services alongside the review of literature (Roth \& Fonagy, 1996) which was commissioned at the same time. Older people are less likely to be referred for psychological interventions than younger adults, although there is no evidence that these treatments are less effective in an older age group. For understandable reasons the literature review only examined randomised control trials of psychotherapy outcome. It therefore missed the information which can usefully be gained from open trials and single case reports. In addition all patients included in the trials met DSM criteria (i.e. they were 'ill' so the value of early psychotherapeutic intervention as possibly preventative (Ardern et al, 1998) was excluded). However, even using these strict criteria it has been noted (Roth \& Fonagy, 1996) positive outcomes for behavioural, cognitive-behavioural and structured psychodynamic psychotherapy for depression; psychosocial interventions for carers: and reality orientation for people with dementia.

Even those who think that psychotherapy in any or all of its facets should appropriately be offered to older patients, tend to divide people into those considered to have organically determined problems and those with psychogenic conditions and are likely to reserve therapeutic zeal for the latter (Schmid, 1990). In reality, organic and psychogenic factors are operating in each individual patient. In a week when clinicians are feeling most hardpressed it is not uncommon for the dementia continuing care ward round to be truncated. When a nursing skill-mix review is undertaken, the most likely outcome on the dementia ward is for trained staff to be replaced by nursing assistants. However, because of the complexity of the needs of dementia patients staff should give the most time, be the most experienced and the most skilled. Terry (1997) writes of the "mindlessness" and "detachment" which can characterise staff attitudes on long-stay geriatric wards. Kitwood (1990) in writing of the "malignant social psychology" which surrounds people with dementia, recognises that often functioning is at a worse level than that determined by the dementia. Affective tone is recognised and responded to long after other abilities are lost (Williams \& Garner, 1998). Having a view of care which involves an empathic approach informed by 
a psychotherapeutic understanding can help us reduce the routine thoughtlessness of some of our management of the most disabled patients.

In assessing the needs of carers, we usually use a stress/burden perspective. This focus often serves us well but it is not always successful. We all know the carer who appears to be quite oppressed by the burden of care and is asking for assistance but either overtly turns down or covertly sabotages everything that is offered to reduce the burden. There are two levels of problem encountered by the care-giver which need to be understood for professionals to be helpful: conscious problems and the burden of coping with a spouse with dementia; and unconscious conflict stimulated by this role and situation (O'Connor, 1993; Garner, 1997a).

\section{Positive factors and recent developments}

Old age psychiatry has been a separate speciality since 1989. Good services are developing around more manageable catchment areas. Practitioners are now more able to think about the type of service and the quality of care they provide.

The early attitudes of traditional psychoanalysis that could have been considered elitist are changing and psychotherapists are becoming involved with different patient groups (e.g. those with learning difficulties) (Sinason 1992). Jacques (1965) described the 'mid-life crisis' in which the finiteness of time confronts people who in young adulthood hold onto the fantasy of immortality and unlimited prospects for their ambitions. He was writing of patients 10 or 20 years younger than those referred to old age psychiatry services. However, Ardern (1997) points out that this milestone can be postponed until retirement and its recognition may provide therapeutic opportunities. Segal (1958) writes of the successful analysis of a 73-year-old man in whom the unconscious fear of death, increasing with old age had led to a psychotic breakdown. Erikson's developmental life cycle approach (1966) has been taken up by later workers (e.g. King, 1980; Hildebrand, 1982). They consider that people of any age came to therapy when developmental adaptation breaks down. The Freud museum conference in 1996 exclusively addressed problems associated with old age in Psychoanalysis and the Future of Ageing (Garner, 1997b).

Life review, which is part of all therapy, is a familiar and much used concept in old age psychiatry and could be the basis on which to develop therapeutic techniques.

The College has produced guidelines for psychotherapy training (Grant et al, 1993) so that many more psychiatrists, including those specialising in old age, will have been exposed to and had some training in different forms of therapy under supervision.

A number of services offer cognitive-behavioural therapy for individuals and groups of older patients in a variety of settings. Some now have a regular clinic or workshop for couple and family work where the referred patient is an older adult (e.g. Benbow et al, 1990). Similar techniques are used when families are coping with dementia (Benbow et al, 1993).

The Association for Psychoanalytic Psychotherapy (APP) in the NHS founded an older adult section in 1994. This section has endeavoured, with some success, to bring the possibilities of this hitherto neglected area of therapeutic work to greater awareness, both within psychotherapy and within old age psychiatry.

The College reading list now includes a subsection on psychotherapy with elderly people.

The British Psychological Society has a special interest group for the elderly (PSIGE).

Patients take into the senium not only the difficulties and problems they had when younger but also the strengths, internal resources and coping strategies they have used over the years. It is upon these that clinicians could capitalise.

\section{Possible ways forward}

There needs to be continued attitudinal change around therapeutic possibility with older adults. This can be addressed locally through journal clubs, case conferences and other educational meetings and nationally via conferences, workshops, etc. Sandra Evans will be circulating a questionnaire to Faculty members concerning the attitude of consultants to psychotherapy and the provision and configuration of services if they exist. This will raise the profile of psychotherapy with old age psychiatrists. Old age psychiatrists should be taking every opportunity to emphasise the quality of the emotional life of older people as much as physical and social care, for example, the older adult section of the APP has written to the Office of Fair Trading regarding their inquiry into care homes. suggesting that the Office's four areas of concern (information, contracts, finance and redress) would not uncover the subtleties of emotional abuse which may and does easily occur when frail, dependent people are in a position of being cared for by those who are inevitably in a position of power in relation to them (Garner, 1998). Those who are interested should certainly continue to write in this area and try not to be discouraged by what seems a fairly rigid divide between psychotherapy literature and psychiatric journals. It would be helpful if pre-publication referees ask for at least some 
mention to be made of a psychological formulation in psychiatric papers they are sent for review. Topics for audit should be including questions of how much face-to-face interaction takes place between doctors and patients during an admission and not be only about investigation and medication protocols.

Old age psychiatry services should employ a therapist for a number of sessions - this ideal will certainly be thwarted by resources and geography. Where such an arrangement is possible, the psychotherapist could usefully be involved in supervision (Porter, 1996) not only of cases in therapy but also helping staff to increase their understanding of the complex emotional state of each patient (Ardern et al, 1998). Working with patients inevitably older than themselves evokes its own particular feelings for staff (Martindale, 1989; Terry, 1997). It is helpful to understand transference and countertransference projections if they are not to obstruct thoughtful and appropriate care.

Higher psychiatric training in old age psychiatry is now well organised and could accommodate sub-specialisation both within special interest and core sessions. One possible subspecialisation would be psychotherapy.

Placements could be offered in old age psychiatry teams for trainees from independent counselling and therapy organisations needing experience in psychiatry.

Links could be fostered with local psychology services if this does not already happen and with psychotherapy services where they exist. College representatives/tutors in old age psychiatry and psychotherapy could be encouraged to make contact so that links may be formed. Some psychotherapeutic work is being undertaken in the teams but this needs proper supervision.

General professional psychiatric trainees while in an old age post could take on older patients in therapy following the College guidelines and with supervision.

Academics and clinicians with time and energy could contact the research and development committee of the APP which is coordinating multi-centre trials so that older subjects are included in that research.

When purchasers place contracts and set quality standards they should be reminded that the review of NHS psychotherapy services (Department of Health, 1996) places emphasis on equity and accessibility and states that "services appropriate to older adults should be available".

\section{Summary}

This paper may have tended to focus on a psychoanalytic approach because of my particular interest but it also includes other psychological approaches which I have no wish to discount or devalue. The psychoanalytic model is seen to be important in two particular ways: it places special emphasis on the uniqueness of patients (an emphasis to be valued when considering the numbers of referrals seen each week by old age psychiatrists and the numbers of patients living in institutional care, both private and NHS); and the model is also able to address staff fears about this difficult patient group.

Realistically even if each service had sessional input from a therapist, the number of patients being seen for psychotherapy would still be small. However, the aim would be to have the general service informed by a psychotherapeutic approach (in the broadest sense) having regard to the emotional life of the patient. Winnicott (1971) writes of "therapeutic consultation". This is a concept from his work with adolescents but could perhaps teach us something even about how to use 15 minutes in out-patients.

Old age psychiatrists have become adept in thinking of ways to reduce social isolation. The aim of all psychological interventions is to reduce emotional isolation, Hunter (1989) quotes Anthony Storr, who wrote in 1960. "A man's sense of his own identity as a person depends on communication with other persons". That is no less true for an 80-year-old than a 20-year-old. Increasing our psychotherapeutic skills is a way of developing and enhancing our communication with our older patients who deserve no less.

It is hoped that this paper will stimulate discussion, generate ideas and eventually an agreed College policy document may be produced to improve training and service in this area.

\section{References}

ARDERn, M. (1997) Psychotherapy and the elderly. In Advances in Old Age Psychiatry: Chromosomes to Community Care (eds C. Holmes and R. Howard). pp. 265-276. Petersfield: Wrightson Biomedical.

-. Garner, J. \& PORTER, R. (1998) Curious bedfellows: psychoanalytic understanding and old age psychiatry. Psychoanalytic Psychotherapy. 12, 47-56.

BENBOW. S. M., Egan, D. \& MARRIOTT, M. A. (1990) Using the family life cycle with later life families. Journal of Family Therapy, 12, 321-340.

-. MARRIOTT, A., MORLEY, M., et al (1993) Family therapy and dementia: review and clinical experience. International Joumal of Geriatric Psychiatry, 8. 717-725.

BELL. D. (1996) Primitive mind of state. Psychoanalytic Psychotherapy, 10, 45-57.

DEPARTMENT OF HEALTH (1996) NHS Psychotherapy Services in England: Review of Strategic Policy. London: HMSO.

ERIKSON. E. (1966) Eight ages of man. Intemational Joumal of Psychoanalysis, 2, 281-300.

Evans, S. (1998) Beyond the mirror: a group analytic exploration of late life and depression. Aging and Mental Health, 2, 94-99. 
FREUd, S. (1905) On Psychotherapy. Reprinted (1953-1974) in The Standard Edition of the Complete Psychological Works of Sigmund Freud (trans. and ed. J. Strachey). vol. 7. pp. 257-268. London: Hogarth Press.

GARNER, J. (1997a) Dementua: an Intimate death: anticipatory or current grief? British Journal of Medical Psychology, 70, 177-184.

- (1997b) Freud and old age: psychoanalytic aspects of ageing. Old Age Psychiatrist. 8. 4.

- (1998) Open letter to the Director General of Fair Trading. APP Newsletter, 22, 4-5.

- \& Evans. S. (1996) Psychodynamic perspectives in old age psychiatry: a necessary integration. (APP Conference Report). Psychiatric Bulletin. 20. 111.

- \& ARDERN. M. (1998) Reflections on old age. Aging and Mental Health, 2, 92-93.

Grant, S.. Holmes, J. \& Watson, J. (1993) Guidelines for psychotherapy training as part of general professional psychiatric training. Psychiatric Bulletin. 17. 695-698.

HILDEBRAND. P. (1982) Psychotherapy with older patients British Journal of Psychological Medicine, 55, 19-28.

HUNTER, A. J. G. (1989) Reflections on psychotherapy with ageing people individually and in groups. British Journal of Psychiatry. 154, 250-252.

JACQUES. E. (1965) Death and the mid-life crisis. International Journal of Psychoanalysis, 46. 502-514.

KING. P. (1980) The life cycle as indicated by the nature of the transference in the psychoanalysis of the middleaged and elderly. International Journal of Psychoanalysis, 61, 153-160.

KITwOoD, T. (1990) The dialectics of dementia: with particular reference to Alzheimer's disease. Ageing and Soclety. 10, 177-196.

MARTINDALE, B. (1989) Becoming dependent again: the fears of some elderly patients and their younger therapists. Psychoanalytic Psychotherapy. 4, 67-75.
MEERLOO, J. A. M. (1955) Psychotherapy with elderly people. Geriatrics, 10. 583-587.

O'CONNOR. D. (1993) The impact of dementia: a self psychological perspective. Journal of Gerontological Social Work, 20, 113-128.

PORTER. R. (1996) The psychoanalytic psychotherapist and the old age psychiatry team. In Psychiatry in the Elderly (2nd edn) (eds R. Jacoby \& C. Oppenheimer). pp. 251268. Oxford: Oxford University Press.

ROTH. A. D. \& FONAGY. P. (1996) Psychotherapy: What Works for Whom? New York: Guilford Press.

SchmiD, A. H. (1990) Dementia, related disorders and old age: psychodynamic dimensions in diagnosis and treatment. American Journal of Psychoanalysis, 50. 253-262.

SEGAL. H. (1958) Fear of death: notes on the analysis of an old man. International Journal of Psychoanalysis, 39. 173-181.

Sinason V. (1992) Mental Handicap and the Human Condition. New Approaches from the Tavistock. London: Free Association Books.

STORR. A. (1960) Torture without violence. New Statesman. 12 March. 358.

TERRY, P. (1997) Counselling the Elderly and their Carers. Basingstoke: Macmillan.

WILLAMMS, D. \& GaRNER, J. (1998) Affective memory in dementia. British Journal of Psychiatry. 172. 379-380.

WinNicoTt. D. W. (1971) Playing and Reality. London: Tavistock.

ZiviAn, M. T., LARSEN, W., Knox, V. J., et al (1992) Psychotherapy for the elderly: psychotherapists preferences. Psychotherapy, 29, 668-674.

Jane Garner, Consultant Psychiatrist, Department of Old Age Psychiatry. Chase Farm Hospital, The Ridgeway. Enfield, Middlesex EN2 8JL

\title{
Disruption of children's lives by maternal psychiatric admission
}

\author{
Valerie Hawes and David Cottrell
}

\begin{abstract}
Aims and method The aim of the study was to investigate changes in child care arrangements after admission of mothers to acute psychiatric wards. Data were collected by interview where possible and from case notes.

Results Twelve out of 53 children of mothers interviewed had to move house. Chronicity of psychiatric disorder was evident in half the mothers. Clinical implications Children's lives are affected by maternal psychiatric admission with the likelihood of repeated disruption where psychiatric disorder is chronic.
\end{abstract}

Over the past five decades there has been considerable research, both epidemiological and clinical, which described the consequences for children of parental psychiatric disorder. Much of this research has been reviewed and its practical applications discussed in Gopfert et al (1996). However, it seems that such knowledge has had relatively little impact on the psychiatric care of patients who are also mothers. In the context of risk assessment of mothers, Oates (1997) has pointed out that there are no questions relating to child care in the Health of the Nation Outcome Scale. 